\title{
Erratum to: Establishment of testicular and ovarian cell lines from Honmoroko (Gnathopogon caerulescens)
}

\author{
Shogo Higaki $\cdot$ Yoshie Koyama $\cdot$ Emi Shirai · \\ Tomoya Yokota $\cdot$ Yasuhiro Fujioka \\ Noriyoshi Sakai $\cdot$ Tatsuyuki Takada
}

Published online: 8 January 2013

(C) Springer Science+Business Media Dordrecht 2013

\section{Erratum to: Fish Physiol Biochem \\ DOI 10.1007/s10695-012-9733-y}

Unfortunately, the acknowledgement contained an incorrect academic degree for Koji Ninomiya and the name of Muneji Ujiie was misspelt in original publication of the article. The correct first sentence of the acknowledgement should read as "The authors thank Koji Ninomiya and Muneji Ujiie, Shiga Prefectural Fisheries Experimental Station, for providing Honmoroko (Gnathopogon caerulescens)."

The online version of the original article can be found under doi:10.1007/s10695-012-9733-y.

\section{S. Higaki · Y. Koyama · T. Takada}

Ritsumeikan Global Innovation Research Organization, Ritsumeikan University, Nojihigashi 1-1-1, Kusatsu,

Shiga 525-8577, Japan

E. Shirai · T. Yokota $\cdot$ T. Takada $(\bowtie)$

Laboratory of Cell Engineering, Department of Pharmaceutical Sciences, Ritsumeikan University, Nojihigashi 1-1-1, Kusatsu, Shiga 525-8577, Japan

e-mail: ttakada@ph.ritsumei.ac.jp

Y. Fujioka

Lake Biwa Museum, Oroshimo 1091, Kusatsu,

Shiga 525-0001, Japan

\section{N. Sakai}

Genetic Strains Research Center, National Institute of Genetics, Mishima, Shizuoka 411-8540, Japan 